\title{
Editorial:
}

\section{The birth of a journal}

Sri Venkateswara Institute of Medical Sciences (SVIMS) was established in the year 1993 with a view to providing quality medical care at a nominal cost to the poor and needy. In 1995, SVIMS became a University by an act of Andhra Pradesh State Legislature. In 2006, the Government of India included SVIMS as one of the institutions for upgradation at par with All India Institute of Medical Sciences (AIIMS), New Delhi under the Pradhan Mantri Swasthya Suraksha Yojana (PMSSY) scheme.

Major objectives of SVIMS include creating a centre of excellence for providing medical care, educational and research facilities of a high order in the field of medical sciences; developing patterns of teaching in postgraduate and super-speciality level so as to set a high standard of medical education. Keeping in mind the objectives conceived by the founding fathers of SVIMS, the need for bringing out a peer-reviewed journal was felt. Thus, the Journal of Clinical and Scientific Research was born on the occasion of the institute celebrating its $19^{\text {th }}$ Anniversary on 26 February 2012. The birth of JCSR is a moment to cherish and it heralds a new era in the academic service rendered by SVIMS.

The Journal of Clinical and Scientific Research (JCSR) will be published quarterly, not only in the print format, but also will be available in the "free full-text" format at the institute's website (http://svimstpt.ap.nic.in/jcsr/jhome.htm). The JCSR welcomes electronic submissions and aims at fast-track peer review and rapid publication. Given the paucity of quality peer-reviewed medical journals published from Andhra Pradesh, the JCSR will be an appropriate platform for medical college faculty, postgraduate students and researchers to share their research findings. The JCSR being available online in the free-full text format will enhance accessibility and will facilitate a wide readership world over. It is fondly hoped that the best of research will get published in the JCSR in the years to come!

\section{B. Vengamma}

Hon. Editor-in-Chief

\section{P.V.L.N. Srinivasa Rao}

Exec. Editor-in-Chief

Vengamma B, Srinivasa Rao PVLN. The birth of a journal. J Clin Sci Res 2012;1:1. 